\title{
Critical Proximity
}

\author{
JANE SIMON
}

MACQUARIE UNIVERSITY

This essay is concerned with the question of the 'distance' and 'proximity' between a view and its description and, in a broader sense, between criticism and the texts of which it speaks. In contrast to the tradition of 'critical distance', I argue for a relationship between words and images that allows for words to move towards objects in a manner which enlivens them. Meaghan Morris describes this, in Identity Anecdotes, as a practice of 'embracing a critical proximity to our objects of study rather than seeking a distance from them'. ${ }^{1}$ This essay responds to Morris's description of critical proximity, and addresses the idea of proximity in relation to critical writing about the visual. I argue for a critical writing practice which pays attention to the variable degrees of nearness between criticism and its object, and which seeks to respond to texts on their own terms.

Approaching and writing about texts on their own terms entails foregrounding the specificities and capacities of the medium in question. To question what it means to talk in one medium about the practices of another medium is an essential part of a critical practice that approaches texts on their own 
terms. How can a writing practice be responsive, and indeed sympathetic, to the specificities of particular texts and sites? Here, I think through that question by considering the space between words and images. This supple space is explored with three examples which demonstrate the activity of looking and the productivity of describing that practice. Rather than speak in general terms about an ideal closeness between a critic and a text, I tease out the degrees of nearness and distance between words and objects of vision. I begin by discussing the role of description in writing about images in relation to Michel Foucault's Death and the Labyrinth: The World of Raymond Roussel in order to draw attention to a mode of looking-and a critical mode of describing that looking-which is fussy in its attention to all objects and details within a frame of vision.

I go on to consider the conceptual art practice of Ian Burn and his attention to how we look at art through, and with, words. I suggest that Burn's critical art and writing practice demonstrates the unnecessary split between the material and the conceptual or, to put it another way, between visual experiences and written ideas. The essay concludes by reflecting on Morris's response to Lynn Silverman's photographs of the Australian desert, arguing that Morris's essay is an example of 'critical proximity'.2 By bringing together a marginal work of Foucault on an experimental writer of the early 1900s, an Australian artist's work and writing from the 1960s to the 1990s and a piece of writing by Morris from the 1980s that has received little attention, I am arguing for a mode of critical proximity that is not only spatial, but also temporal. That is, while cultural studies is alert to contemporary aspects of culture, this needn't entail, I argue, a critical distancing of objects and practices of the past. ${ }^{3}$ By bringing these examples together, I'm suggesting that there remain cues in this work that might compel cultural studies' present. Thus, looking at Foucault's writing on literature, the work of an Australian conceptual artist and Morris's writing on art and photography means that this essay also enacts another relationship of proximity: towards the periphery of cultural studies' preferred range of objects. By bringing these marginal (in cultural studies, at least) examples together, I demonstrate their relevance and critical proximity to cultural studies' present. 
—LUMINOUS, PATIENT, SIMPLE THINGS

Sometimes a momentary reflection shines

In the view set into the penholder's tip

Against which my wide-open eye is glued

At a tiny distance, barely held away;

The view is fixed inside a ball of glass

That is small and yet quite visible, tightly clasped

At the top, almost the end of the white penholder

On which red ink has left quite blood-like stains

The view is the very thinnest of photographs

Probably imperceptible to go by

The thickness of the piece of glass which is

Left rough on one side, on the back; but all

This is enlarged when a more curious eye

Comes close enough for a lash briefly to touch. ${ }^{4}$

Raymond Roussel's poem opens up an endless panorama from the tiniest of views. The image of an eye pressed up to an almost imperceptible picture-'the very thinnest of photographs'-within the minute lens of a souvenir pen draws me to questions about proximity, scale and the organisation of perspective. Roussel's eye pressed 'at a tiny distance' up to a tiny image in the top of his souvenir pen is an image that prompts us to think about the nature of proximity in critical writing.

Published in 1904, Roussel's La Vue consists of three poems, 'La Source', 'Le Concert' and 'La Vue'. Each poem offers a meticulous description of a small tableau. 'Le Concert' writes the detail contained in the small sketch at the head of a letter written on hotel stationery. 'La Source' begins in a restaurant observing a couple and zooms in to the image printed on a bottle of mineral water, only to zoom out again when the bottle is removed by a waiter. This intensive description of what falls within the scope of Roussel's 'lens' is most elegant in 'La Vue', when he peers into the souvenir pen. 'La Vue' is an obsessive description of the view offered by the tiny panorama. ${ }^{5}$

An image of an eyelash brushing against the glass lens of a pen to peer at the view is a fitting vision for a model of thinking and writing which is driven to notice detail, the surface and the minute. 'La Vue' emphasises the minute, the microscopic: 
insistent details and gestures. Roussel writes about a wooden stick that a child is about to throw to a dog:

The piece of driftwood leaves the child's right hand;

It is a thin piece from a plank, with a split

At one end; and this split is tightly closed,

It curves along a slightly sloping line

But does not run a very long distance;

The rest of the white wood has kept its strength;

Its whole consistency is left intact;

The wood is not exactly horizontal,

Though close to the beginning, the split end,

Perhaps because it is heavier, descends ${ }^{6}$

Roussel's depiction of the very small view provided by the tiny photograph in the top of his penholder describes objects and subjects with the same careful consideration. This exacting detail of the shape of the piece of driftwood is also given to the child's absorption in his task of throwing the stick, the colour of the child's skin, the folds of his socks, and the mark of his sock where the sun has tanned his skin. 'La Vue' moves from detailing an expression on a woman's face to the way her hand moves, and on to the way the wind makes the canvas of a sail flap. Wrinkles on faces, marks on the sand and a stream of smoke from a yacht are knitted together in a beatific description of a holiday beach scene which is painstakingly mapped out over forty-nine pages. Roussel's tiny vue is immense, and demonstrates how the linguistic and the visual can trace each other's surfaces.

Writing about the small lens on the pen which inspired 'La Vue', Foucault slides into a description which is equally responsive to particularities as the poem itself:

It is precisely the glass lens, mounted on the souvenir pen, that offers the roundness of an infinite landscape. It's the marvellous instrument for constructing words which with a basic generosity gives out something that can be seen: it is a slender piece of white ivory, long and cylindrical, topped with a palette and a faded description; and toward the bottom, an ink-stained metal band. A lens hardly larger than a brilliant dot opens, in 
the middle of this instrument manufactured to draw arbitrary signs on paper, not less distorted than itself, a space of luminous, patient, simple things. ${ }^{7}$

Foucault's description of the pen draws attention to the instruments-the tools-of writing. ${ }^{8}$ The luminous, patient, simple things that Roussel draws our attention to are, Foucault reminds us, constructed by technologies of writing-arbitrary signs on paper. And both Roussel and Foucault remind us that the surface across which singularity plays is situated between words and things. Roussel's 'La Vue', together with Foucault's response to Roussel, provides an opportunity to think about the role of detail and contiguity in description, and demonstrate how language might grapple with the visible. I argue that what is important in Roussel's poem, and Foucault's discussion of it, is the relationship between the very small frame of vision, that requires-or demands-to be looked at closely (the only way of seeing the minute photograph is to press one's eye right up to the pen) and the 'generous' prolific description that looking at it produces.

-PERIPHERAL VISION

Foucault's response to Roussel in Death and the Labyrinth resonates with Roussel's model of description. Foucault's and Roussel's models of description exemplify how to write about visible objects and events in a manner which lets the minute and the obvious shimmer against one another. This requires, I argue, a mode of looking which notices the peripheral and the detail.

While waiting, I found my attention drawn to a series of books of that faded yellow color used by publishing firms of the late nineteenth, early twentieth centuries; in short, books the likes of which aren't made anymore ... I selected a book out of curiosity to see what José Corti was selling from the stock of the Lemerre firm, and that's how I came upon the work of someone I had never heard of named Raymond Roussel, and the book was titled La Vue. ${ }^{9}$

Stumbling across the books of Roussel in Corti's famous Parisian bookstore resulted shortly after in Foucault writing Death and the Labyrinth. Foucault describes Death and the Labyrinth as the book he wrote 'most easily, with the greatest pleasure', but also as a gratuitous task, one which he doesn't see as having a 
place within the sequence of his other books. ${ }^{10}$ Foucault is unabashed about his passion for Roussel. In an interview he describes Roussel as his 'love for several summers ... no one knew it', confiding his seduction by the methodical process of Roussel's writing. ${ }^{11}$

Despite Foucault's doubts about how Death and the Labyrinth fitted in his oeuvre, the propensity for careful description in this work can be traced throughout his other writings. Deleuze, in his monograph on Foucault, describes Foucault's connection with Roussel through their shared enthusiasm for description. He notes:

Foucault's passion for describing scenes, or, even more so, for offering descriptions that stand as scenes: descriptions of Las Meninas, Manet, Magritte, the admirable descriptions of the chain gang, the asylum, the prison and the little prison van, as though they were scenes and Foucault were a painter. No doubt this is due to his affinity, to be found throughout all his work, with the new novel and with Raymond Roussel. ${ }^{12}$

Deleuze is one of the few commentators on Foucault's work who situates Death and the Labyrinth within the context of his other writings. ${ }^{13}$ Foucault denounces any real connection between Death and the Labyrinth and the rest of his oeuvre-'No one has paid much attention to this book, and I'm glad; it's my secret affair', he writes. ${ }^{14}$ Yet a concern with the mapping of visibility and what can be articulated from what can be seen is present in several of his works. ${ }^{15}$ I argue that consideration of Foucault's attention to the detail of description reveals the productive nature of description. Description is not mere transcription of the visual; it actively makes something visible-it is generative. ${ }^{16}$

Foucault's 'seduction' by Roussel's obsessive methods of writing results in him responding to Roussel with a similar obsessive-and pleasurable-method of reading. Elspeth Probyn's discussion of Death and the Labyrinth is animated by the delight that Foucault takes in his reading of Roussel. She writes, 'It is a curious thing: Foucault bent over, following the minuteness of Roussel as one might trace by finger the curves of a map in relief, as one might learn by finger the quirks of a lover's body'. ${ }^{17}$ Probyn's description here points to the close reading practice that Foucault undertakes-just as Roussel peers closely at his tiny view, Foucault 'traces by finger' Roussel's descriptive poem. For Probyn, Foucault's work on Roussel is important for 
its attention to questions of surface, to the technology of writing, and to the consistent un-hierarchical attention to objects in the texts of Roussel. ${ }^{18}$

Foucault's mapping of Roussel's distinctive world has elsewhere been commented on as a mirroring of writing style. James Faubion's introduction to Death and the Labyrinth highlights how Foucault's writing in the monograph mimics the literary style of Roussel's own writing, how 'Foucault seems to dissolves into Roussel, to speak in Rousselian tongues'.19 Foucault writes about Roussel in the terms set by Roussel in his own writing. If 'Foucault seems to dissolve into Roussel' (and what could be more proximate than dissolving into a subject) this is because there is an intent in Foucault's book to reading and writing about Roussel in a manner responsive to the minuteness of Roussel's own writing.

-DETAIL, DETACHMENT, DESCRIPTION

For Foucault, Roussel's writing highlights that 'between what is hidden within the evident and what is luminous in the inaccessible, the task of language is found'. ${ }^{20}$ This figuring of language as investigation-revealing the invisible and noticing the inaccessible-suggests a model of writing which, in describing a view, creates another way of looking at that view. Foucault's Roussel opens up new zones of perception through particular technologies of writing. These zones of perception are brought into focus by a literary style which flexes words towards things, without distinguishing between the visible and invisible, the perceptible and imperceptible, the minute and the obvious:

It is as if the language carefully applied to the surface of things to describe them were thrown out again by a prolixity inherent in these things. The laconic vocabulary of description is blown up by all the discourse of what usually is never apparent. Little by little this unwonted and chatty visibility takes over the whole field of perception and opens it up for a language that then replaces it: everything begins to speak a language that is visible, and its invisible content is made visible. ${ }^{21}$

Description here is not mere infill; it is productive in itself. That the language of description opens up the field of perception positions Roussel's descriptions as a project of translation from the visible-and indeed invisible-to the linguistic. Roussel's attempt to proximate the sensual, visual and linguistic produces a 
descriptive skin which is 'as close as possible to the being which becomes perceptible through it'.22 Roussel's writing is language as inventory, and it is his involved description of each object, gesture and movement which appears in the lens that establishes a surface along which the invisible is made visible.

Susan Stewart describes Roussel's 'La Vue', 'Le Concert' and 'La Source' as examples of 'rewriting', suggesting that each poem takes a form of visual representation and tries to 'rewrite' it in the medium of written language. ${ }^{23}$ For Stewart, the tableaux of the three poems (the tiny picture atop the pen, the stationery letterhead, the label) operate as a rebus-as pictures that spell out messages-but what she finds most interesting is Roussel's strategy of presenting readers with the 'writing of a rebus, not with a rebus itself'. ${ }^{24}$ By describing a representation within a representation Roussel keeps his reader aware of how the minute scenes are being written, and the very minuteness of the scenes highlights the infinite possibilities of description.

'La Vue' consistently maps out details not according to their apparent importance but merely because they appear in Roussel's view as his eye scans the tiny panorama. Of Roussel's technique, Stewart suggests, 'Everything seen is equally describable; the point of origin is simply a point of origin, a place to begin in this gliding across the unruffled surface of things'. ${ }^{25}$ Gliding is an appropriate word to describe Roussel's mode of writing. ${ }^{26}$ In 'La Vue', when describing a laughing helmsman, Roussel describes both the helmsman's body as well as the spaces where the edge of his body joins the more distant perspective of the sea:

The biggest, whose Herculean back we see,

Is happy; his broad shoulders can be seen

Shaking with laughter at some clever joke;

$\cdots$

His two elbows alike, though next to his trunk

Are far enough away to leave a space

Through which one sees the waves far out there curving Incessantly ...27

There is a kind of cinematic panning at play here-a sweeping which doesn't refocus on particular objects or faces. Roussel's words describe-and glide across-the 
surface of a scene with little regard for establishing perspectival depth. That is, Roussel's 'lens' does not focus and establish proportion and perspective according to each object or gesture. Instead, if there is perspective, it is all seen frontally, from the same position and with the same regard: what Foucault describes as 'an orthogonal presentation of things'. ${ }^{28}$ The helmsman's elbows and trunk intersect the curving waves, but their proportions are not distinguished. What is distinguished is the spatial positioning of each thing. 'La Vue', in particular, maps out gestures and objects according to how they correspond to each other:

she lifts both arms

A little above her knees; her left hand raised

Cuts through the motion of the distant sea

To stop at a small boat which it conceals ...29

The woman's left hand-situated precisely above her knees-directs Roussel to a small boat which it then hides. These gliding connections show how each located entity in the poem-an elbow, a curving wave, a left hand, a small boat-'is never defined in relation to the whole but according to a system of directions of proximity passing from one to the other as if following the links in a chain'.30 'La Vue' includes the following directions: 'Further off to the right', 'behind this curtain', 'in all directions', 'upward in a straight line', 'toward the sea', 'behind his back', 'to the left away from the sea', 'before them', 'further left', 'around the steeple', 'in the middle', 'at this point', 'still quite close', 'behind the rock', 'right at the left hand edge', 'further up the slope', 'higher up', 'below the lighthouse', 'twenty yards ahead', 'opposite him'. ${ }^{31}$ What is crucial here is the emphasis on the relationship of proximity between things regardless of whether they are an object clearly situated in the foreground, or a barely visible detail in the distance. Roussel's mode of looking directs us from the minute to the obvious while highlighting how they exist in a connection of proximity.

This endless list of directions leads us from characters and their movements to objects and a moving sea without priority. This un-hierarchical attention makes us attend to detail across the entire frame, and rearranges perspective to consider peripheral details as a matter of course. 'La Vue' and Foucault's reading of Roussel both reveal the ability of language to ceaselessly describe the visible. Further, these 
works offer an example of a mode of looking that traverses the distance between objects and the words used to represent them.

\section{—LOOKING AT SEEING AND READING}

Thus far this essay has considered descriptive richness and a non-hierarchical way of looking as a means of grappling with the space between words and things. I move now to reflect upon the relationship between criticism and visual objects using the critical writing and art practice of Ian Burn. While Foucault and Roussel have provided a means to attend to the nature of proximity in description and its objects, with Burn's work I think through how proximity might figure in rethinking the relationship between the materiality of an artwork and the critical ideas used to discuss an artwork.

Burn is useful for his understanding of how art is viewed through and with institutional frames and codes and for his attention to the nuances of language in describing visual experiences. ${ }^{32}$ Burn explicitly considers the relationship between art and theory about art by exploring the process of looking in a number of his artworks. His critical and artistic projects insist on a distinction between two modes of reception of art-what he terms 'seeing' and 'reading'. Burn parallels reading with the project of interpretation of an artwork. He is critical of this, discouraging forms of theorising that try to apply theoretical concepts to works of art in a manner which blankets the art work itself. He explains this with the following comparison:

An analogy that keeps coming into my head is of a painting being designed like flypaper, grabbing at bits of text as they fly past; then someone comes along and writes about what has stuck to the flypaper but does not bother to look at the flypaper itself. 33

Burn refuses to distinguish between the artist creating an 'experience' and the critic providing the 'ideas' based on an interpretation of the experience. Instead, he places responsibility for ideas with the artist and resists the notion of images being read 'into' theory. ${ }^{34}$

Burn's 'Value-added' Landscapes (1992-1993) exemplify this refusal to consider interpretation and visual art as discrete practices. ${ }^{35}$ The paintings which form the basis of the 'Value-added' Landscapes series were collected by Burn in junk shops and secondhand markets. All the paintings are landscapes, and all bear the 
tenderness and untrained practice of the amateur painter. The paintings all look vaguely familiar, due to the habitual appearance of similar items in many suburban Australian homes.

The amateur paintings are hung behind a pane of reflective Perspex glass which is covered with text made of vinyl lettering. The text comments on the painting, describing, critiquing, contextualising and imposing a screen of language through which to view the image. The reflective surface of the Perspex pane in front of the painting in the 'Value-added' Landscapes acts to implicate the viewer in the work. The viewer can't look at the words and the painting without also acknowledging her presence as a spectator, which both adds to and produces meaning in the work. ${ }^{36}$

In 'Value added' Landscape \#11 (1993) blue words interweave with the painting. Some text boldly contrasts with a pink-toned sky, while other words appear across a river, quietly revealing themselves against a background of the same colour. This fragmented reading of the text means that the spectator's eyes must continually shift between easily reading the text-the words 'ideology' and 'vigilant informality' are clear-and peering hard at the sentence bleeding into the blue river: 'a continuum of vision invents translation distancing image and description'. In the same way that the landscape is obscured by the layer of words, the detail of the painting obscures the blue letters.

The layering of image and text means that you can never look at one in isolation. You can't read the criticism without looking at the painting at the same time, and, because the colour of the text often matches the colour in parts of the painting, the words and image bleed into each other. The 'Value-added' series questions the proximity of criticism to texts, and the physical act of reading criticism in relation to actually looking at images or paintings. Burn suggests that the 'Value added' Landscapes transform:

both text and image, leaving a sense of incompleteness attached to each element. Part of the text describes the picture, other bits offer no match, positioning the text 'out of registration' with the picture. Hence the picture can never quite anticipate or displace the text, or the text substitute for the picture. ${ }^{37}$ 
The 'Value added' landscapes refuse a reception in the form of 'reading', as Burn describes it. They instead invite a response aligned with Burn's description of 'seeing'. 'Seeing', in Burn's use of the word, has less negative connotations than 'reading'. Seeing, for Burn, does not seek to produce meaning out of an artwork, but rather to attend to the materiality of the artwork and the conditions under which we see. Burn argues that 'seeing isn't merely a set of psychological responses but a theory-laden process, with conceptual sets or patterns which organise our seeing prior to and during our seeing'. ${ }^{38}$

Perception, in Burn's understanding, is informed by 'the different layers or regimes of vision'. ${ }^{39}$ Burn's use of the word 'regime' is striking, suggesting a systematic, authoritative hold on our vision, our way of seeing. What is important about Burn is his highlighting of the ways in which seeing is contingent upon context and social values which organise our vision. To illustrate this contingency, Burn uses the example of trying to see a surface of a mirror rather than the reflection a mirror produces:

To 'see' (produce, project) the mirror surface demands concentrated effort, which may be assisted by focusing on imperfections, dust, smears, haze, steam (that is, by the mirror's inability or failure to be a perfect mirror). The extent to which we are able to see the mirror surface irrespective of these incidental factors depends on a self-consciousness of the possibilities of seeing: on being able to look at ourselves seeing, and on being able to interpret our not-seeing of the surface. The instability of perception is encoded within that critical faculty, indexed to the (density of) social and historical constructs underlying how we see, and to the discursive factors which produce our seeing and organise value. 40

This simple example of the activity of looking at oneself through a mirror and noticing the surface of the mirror rather than the image it reflects, suggests that attention to how we look-and the instability of that how-is as important as what we are looking at. Critical writing about the visual needs to be pay heed to the conditions under which we look. Consideration of the variable regimes of vision is part of a practice of critical proximity which aims to write about images on their own terms. 
Burn offers a rethinking of the distance and distinction between critic and artist, words and visions, asking us to consider the proximity of words and things. I want to conclude with an example of 'critical proximity' which ties together this essay's concern with the relationship between seeing and reading, language and vision.

—LOOKING WITH

What remains is a set of tracks. Not the single broken line of the traveller marking a progress on a map; but a double line, an exploration of reversibility, the trace of a movement of a strange, still space in which everybody looks at elsewhere, and somebody looked at here. ${ }^{41}$

In The Pirate's Fiancée, Meaghan Morris describes her method of critical response as reading 'the texts in question sympathetically'.42 For Morris, reading texts sympathetically doesn't mean reading them uncritically, but rather with a critical disposition that responds to the texts in question. She reads texts sympathetically 'in order to understand them as criticisms of those answers that my feminism might automatically provide, and so to use them to question my own assumptions and practices in the process of reading theirs'. ${ }^{43}$ This method of reading and responding is cognisant of the ways in which criticism and texts can effectively inform each other. It requires willingness to exchange, and an avoidance of the knee-jerk reaction of 'answering back'. ${ }^{44}$ Like Foucault's pleasurable curiosity in writing back to Roussel with an equal intensity of detail and description, and Burn's insistence that the relation between words and things is best understood as one of mutuality (where one needn't rule over the other), Morris's sympathetic model of critique allows words to move closer to its objects.

Morris exemplifies this approach in an essay from The Pirate's Fiancée entitled 'Two Types of Photography Criticism Located in Relation to Lynn Silverman's Series'. Silverman's photographs, and Morris's response to them, are interesting for several reasons. As a series, Silverman's photographs present questions and ideas about perception and space, and the way we experience Australian landscape. As an essay, Morris's double critique is inventive and clearly responsive to the form and gestures of the photographs themselves. 
Silverman's photographs are a series of landscapes of inland Australia, taken in New South Wales, South Australia and Queensland. Silverman pairs her photographs, coupling a photograph of the desert floor and the objects that fall within that viewpoint-Silverman's own boots, rocks, grassy clumps, dead birds, desert flowers-with a photograph of the horizon line's seemingly endless variations of sky and cloud canopies, photographed from the point at which the downward gazing photograph was taken. As such, the viewer's eye pores over intimate detail of the desert floor, while simultaneously changing the perspective to the expanse of the horizon from that point. Silverman asks her viewer to look down, and closely, as well as look up and to the distance.

Morris responds to this division-or connection-of perspectives with two manners of critique, as suggested by the title of her essay 'Two Types of Photography Criticism Located in Relation to Lynn Silverman's Series'. The two models of critique run across the page and are divided on the page by the photographs themselves. This means that the reader is forced to follow Morris's critique across a double page, while the horizon line of the photographs, as well as the other critique, remain in the reader's peripheral vision. The reader is therefore constantly aware while she is reading one essay that another one exists. This mimics Silverman's tactical use of the diptych, which necessitates that while looking at the desert floor or the horizon the viewer is always aware of another point of perception.

The placement of text and images on the page is as important as the writing itself. Morris's unconventional split essay is a direct material response to the series in question. As the title of the essay suggests, Morris is carefully, but also playfully, aware of the importance of not privileging the criticism over the photographs. Thus the writing and the photographs effectively inform each other. The typical placement of photographs amongst text in critical essays suggests a very different relationship between criticism and the object of study-one which quite literally has the effect of the writing swallowing up the photograph. In this case, the photographs and writing run alongside each other and neither is stifled by the other.

Just as Silverman plays with ideas about perception and viewpoint, so too Morris highlights the role of perception in viewing photographs and reading criticism. The first 'type' of photographic criticism, which is placed on the page just 
above the horizon photographs, doesn't mention the photographs at all, or the experience of viewing them. Instead, it discusses the myths and cultural experience of the Australian desert. Often this cultural experience is indirect-most city dwellers haven't experienced inland Australia-but one that occurs through myth, postcards and generalised abstract ideas about what the desert is actually like. As Morris speculates:

Signposted yet sign-effacing, it is a space accorded the status of a reservoir of places where nothing might be, or anything might happen. In traditional legend, birds fly backwards there; rivers run against nature, the sand spawns fishes, and inland seas are lapping just beyond the dry horizon. In contemporary speculation, lost creatures reappear and vanish; regions belong obscurely to alien powers, while the wasteland hides a monstrous proliferation of caverns breeding new forms of experimental warfare. 45

This first 'type' of criticism, which is obviously linked to the 'theme' of the photographs, describes the detached experience of the desert, while simultaneously remaining detached from the photographs themselves. In a similar manner, the photographs of the horizon are obviously related to those of the desert floor, yet they remain at a distance-they could upon first glance be a horizon of the sea, or indeed any flat horizon, anywhere.

The second type of photographic criticism, like the photographs of the desert floor, is more 'intimate'. Here, Morris writes specifically about the photographs and the experience of viewing them, as well as their formal arrangement. She refers to the different ways the eye can wander over the photographs: 'You could go on and on hypnotically linking horizon lines, effacing frames and poring over precious places'.46 Her attention to how the eye views the photographs echoes the photographer's willingness to draw attention to methods of framing and perspective.

Both 'types' of photographic criticism are prompted by the photographs themselves and together are an example of critical proximity. While the first type of photographic criticism looks outward from the photographs to their wider context (or indeed, horizon), and the second type of criticism peers inwards at the formal details of the photographs, it is precisely this oscillation between distance and proximity which makes it such a crucial example of critical proximity. What becomes 
obvious in reading 'Two Types of Photography Criticism' is the very proximate relationship between the formal detail of Silverman's series and the broader tropes of myth and landscape that Morris directs us to consider. Further, while the two types of criticism differ in their style and effect, they both respond to the terms set by the photographs.

Morris's ethic of writing, so clear in this piece on Silverman, emphasises the particular and the contingent and considers language and the visual to operate on the same terrain. 'Two Types of Photography Criticism' emphasises the particular and the contingent by responding to both the formal qualities of Silverman's series (the formal arrangement of the photographs, the pairing of two different perspectives) and the thematic content of the photographs (their attention to landscape, travel, interiority). When Morris writes 'I see Lynn Silverman's photographs as a study in the construction of inland space', she is indicating that visual practice is itself a critical practice. ${ }^{47}$ Like Burn's insistence on rethinking the notion that artists present experiences, and critics and writers present ideas, Morris has a sympathetic approach to visual practice. By attending to Silverman's photographs as critical and epistemological objects, Morris places language and the visual, criticism and objects, on the same level.

Raymond Roussel's obsessive description in 'La Vue' and Michel Foucault's matching response in Death and the Labyrinth, Ian Burn's critical art and art criticism and Meaghan Morris's sympathetic reading of Lynn Silverman's photographs, considered together, evidence the exacting task of critical proximity: the need to look critically in terms responsible to the object of vision. Each of these writers allows us to view the practice of looking both with and through words. Moreover, considering them together-bringing together work that cultural studies usually distances itself from-is itself a gesture of critical proximity. What Foucault/Roussel, Burn and Morris reveal is that critical proximity is possible-in varying degrees of nearnesswhen seeing and reading, looking and writing, are placed on the same level. Foucault's reading of Roussel highlights how the writer's fussy descriptions produce visibility just as much as they describe a particular vision. Burn's 'Value-added' Landscapes similarly blur the distinction between a view and its description by very 
literally asking us to view the landscape through a pane of words. And Morris demonstrates with her reading of Silverman that written language and vision can flex towards each other.

Proximity as a practice of looking is a form of scrutiny crucial for critical practice. I've suggested that embracing a critical proximity to visual objects of study requires attention to the relationship between words and images. This relationship needn't be one of words drowning out, covering over or interpreting the 'muteness' of the visual. Instead, words can respond to the visual most productively when visual texts are considered, on their own terms, as sites of knowledge. Only then will a practice of critical proximity flourish.

Jane Simon is a lecturer in the Department of Media, Music and Cultural Studies at Macquarie University. She works across the fields of cultural studies, creative research and gender studies. Her current research interests include amateur film and photography, domesticity and the home, and feminist historiography. 
Among the trivial souvenirs acquired at Biarritz before leaving, my favourite was not the small bull of black stone and not the sonorous sea-shell but something which now seems almost symbolic-a meerschaum penholder with a tiny peephole of crystal in its ornamental part. One held it quite close to one's eye, screwing up the other, and when one had got rid of the shimmer of one's own lashes, a miraculous photographic view of the bay and of the line of cliffs ending in a lighthouse could be seen inside.

Cited in Mark Ford, Raymond Roussel and the Republic of Dreams, Cornell University Press, Ithaca, 2001, p. 83.

${ }^{6}$ Roussel, p. 240.

${ }^{7}$ Foucault, Death and the Labyrinth: The World of Raymond Roussel, trans. Charles Ruas, Continuum, London, 2004, p. 117.

${ }^{8}$ Foucault's description resonates with an interview titled 'An Almost Obsessive Relation to Writing Instruments' in which Roland Barthes describes his relationship to different types of pens and the impact they have on the action of writing itself:

When felt-tipped pens first appeared in the stores, I bought a lot of them. (The fact that they were originally from Japan was not, I admit, displeasing to me.) Since then I've gotten tired of them, because the point flattens out too quickly. I've also used pen nibs-not the 'Sergeant-Major', which is too dry, but softer nibs, like the 'J'. In short, I've tried everything ... except Bics, with which I feel absolutely no affinity. I would even say, a bit nastily, that there is a 'Bic style', which is really just for churning out copy, writing that merely transcribes thought. In the end I always return to fine fountain pens. The essential thing is that they can produce that soft, smooth writing I absolutely require.

Roland Barthes, The Grain of the Voice: Interviews 1962-1980, trans. Linda Coverdale, Cape, London, 1985, p. 178.

${ }^{9}$ Foucault, Death and the Labyrinth, p. 173.

${ }^{10}$ Foucault, Death and the Labyrinth, p. 187.

${ }^{11}$ Foucault, Death and the Labyrinth, pp. 187, 174.

${ }^{12}$ Gilles Deleuze, Foucault, trans. Seán Hand, Athlone Press, London, 1988, p. 80.

${ }^{13}$ See Deleuze, Foucault, pp. 47-70. Faubion also notes that there is a connection between Roussel's obsessive concern with language use and Foucault's insistence on the importance of the concept of discourse:

Roussel's preoccupation with the prefabrication of language, with the 'ready-made' and artifactual qualities of words and phrases and sentences, informs Foucault's conceptualization of discourses as scatterings of 'enunciations', of words and phrases and sentences already spoken, of the linguistic but quite material deposits of thought itself. Faubion, p. xiii. 
See also Dennis Hollier, 'The Word of God: "I am dead"', in Timothy J. Armstrong (ed. and trans.), Michel Foucault Philosopher, Routledge, New York, 1992, pp. 136-7, for a brief consideration of the commonality of The Birth of the Clinic and Death and the Labyrinth.

${ }^{14}$ Foucault, Death and the Labyrinth, p. 187.

${ }^{15}$ For example, Foucault wrote Death and the Labyrinth and The Birth of the Clinic at the same time. Deleuze links the two very different books in their approach to statements and visibilities. Deleuze writes:

The first shows how Roussel's work can be divided into two parts: visibilities invented by extraordinary machines, and statements produced by an unusual 'method'. The second book shows how, in an entirely different domain, the clinic and pathological anatomy give rise to distributions that vary between 'the visible and the articulable'. Deleuze, p. 48.

${ }^{16}$ For a discussion which attends to the complex nature of description see Michel Beaujour, 'Some Paradoxes of Description', Yale French Studies, no. 61, 1981, pp. 27-59.

${ }^{17}$ Elspeth Probyn, Outside Belongings, Routledge, London, 1996, p. 30.

${ }^{18}$ Probyn, pp. 31-4. Probyn's reading of Foucault and Roussel is a springboard to conceiving the social as a surface across which 'minute, meticulous, and mundane' desires are articulated and belonging is mobilised according to questions of proximity. Probyn, p. 35. Roussel's consistent detailing of the miniscule-what Foucault describes in Death and the Labyrinth as a 'descriptive epidermis', p. 139gives Probyn an alternative to conceiving identity within a hierarchical model based on firm underlying structures, and instead to insist upon the constantly mutating nature of identity and belonging according to 'processes of singularizing specificity'. Probyn, p. 34.

${ }^{19}$ James Faubion, 'Introduction', in Michel Foucault, Death and the Labyrinth: The World of Raymond Roussel, trans. Charles Ruas, Continuum, London, 2004, p. xi.

${ }^{20}$ Foucault, Death and the Labyrinth, p. 122.

${ }^{21}$ Foucault, Death and the Labyrinth, p. 114.

${ }^{22}$ Foucault, Death and the Labyrinth, p. 139.

${ }^{23}$ Susan Stewart, On Longing: Narratives of the Miniature, the Gigantic, the Souvenir, the Collection, Duke University Press, Durham, 1993, p. 49.

${ }^{24}$ Stewart, p. 50.

${ }^{25}$ Stewart, p. 51.

${ }^{26}$ In Foucault, Deleuze writes 'it is between the visible and its conditions that statements glide.'

Deleuze, p. 66.

${ }^{27}$ Roussel, p. 235.

${ }^{28}$ Foucault, Death and the Labyrinth, p. 109.

${ }^{29}$ Roussel, p. 233.

${ }^{30}$ Foucault, Death and the Labyrinth, p. 109. 
${ }^{31}$ Roussel, pp. 231-76.

${ }^{32}$ For an extensive discussion of Burn's life and art practice see Ann Stephen, On Looking at Looking: The Art and Politics of Ian Burn, Miegunyah Press, Melbourne, 2006.

${ }^{33}$ Burn, 'Less is More, More or Less', Art and Australia, vol. 32, no. 2, 1994, p. 203.

${ }^{34}$ Burn, 'Less is More' p. 203.

${ }^{35}$ For a discussion of the 'Value-added' Landscapes see Piper, pp. 78-9, and Stephen, On Looking, pp.

205-17. For Burn's comments on the series see Burn, 'Notes on “Value Added” Landscapes', Ann Stephen (ed.), Artists Think: The Late Works of Ian Burn, Power Publications, Sydney, 1996, p. 8.

${ }^{36}$ This tactic is even more apparent in Burn's paintings Blue Reflex and Grey Reflex. These paintings are a flat surface of very shiny car paint, and produce subtle reflections of its viewers. Photographic reproductions of these works are beautiful: ghost-like shadows of the viewers and the photographer appear against the surface of the paintings, and become an integral part of the work.

${ }^{37}$ Burn, 'Notes', p. 9.

${ }^{38}$ Burn, 'Art Theory and Perception', in Noel Sheridan (ed.), National Graduate Show and Symposium Papers, PICA Press, Perth, 1992, p. 114.

${ }^{39}$ Burn, Dialogue: Writings in Art History, Allen \& Unwin, Sydney, 1991, p. 177.

${ }^{40}$ Burn, Looking at Seeing and Reading, catalogue essay, University of New South Wales Gallery, Sydney, 1993. Burn's reflection on seeing the mirror's surface is not dissimilar to Roland Barthes' description of seeing through a window to look at a landscape and the shifting focus from the glass of the window to the distance of the landscape:

if I am in a car and I look at the scenery through the window, I can at will focus on the scenery or on the windowpane. At one moment I grasp the presence of the glass and the distance of the landscape; at another, on the contrary, the transparence of the glass and the depth of the landscape; but the result of this alternation is constant: the glass is at once present and empty to me, and the landscape unreal and full.

Roland Barthes, 'Myth Today', in Susan Sontag (ed.), A Roland Barthes Reader, Vintage, London, 1982, p. 110. While Barthes' description is used as an analogy of the relationship between form and meaning in the production of myth, it is nonetheless striking in its cinematic description of the practice of 'looking through'.

${ }^{41}$ Meaghan Morris, 'Two Types of Photography Criticism' in The Pirate's Fiancée pp. 148-9.

${ }^{42}$ Morris, The Pirate's Fiancée, p. 6.

${ }^{43}$ Morris, The Pirate's Fiancée, p. 6.

${ }^{44}$ Morris, The Pirate's Fiancée, p. 6.

${ }^{45}$ Morris, The Pirate's Fiancée, p. 145.

${ }^{46}$ Morris, The Pirate's Fiancée, p. 140.

${ }^{47}$ Morris, The Pirate’s Fiancée, p. 138. 